九州大学学術情報リポジトリ

Kyushu University Institutional Repository

Effect of Pre-treatment Techniques on Physical, Mechanical and Durability Properties of Oriented Strand Board Made from Sentang wood (Melia excelsa Jack)

Iswanto, Apri Heri

Department of Forestry, Faculty of Agriculture, North Sumatera University

Febrianto, Fauzi

Department of Forest Products, Faculty of Forestry, Bogor Agricultural University

Wahyudi, Imama

Division of Wood Processing, Department of Green Resources Utilization, Korea Forest Research Institute

Hwang, Won-Joung

Division of Wood Processing, Department of Green Resources Utilization, Korea Forest Research Institute

他

https://doi.org/10.5109/18854

出版情報: 九州大学大学院農学研究院紀要. 55 (2)，pp.371-377，2010-10-29. Faculty of Agriculture, Kyushu University

バージョン :

権利関係: 


\title{
Effect of Pre-treatment Techniques on Physical, Mechanical and Durability Properties of Oriented Strand Board Made from Sentang wood (Melia excelsa Jack)
}

\author{
Apri Heri ISWANTO ${ }^{1}$, Fauzi FEBRIANTO ${ }^{2}$, Imam WAHYUDI ${ }^{2}$, Won-Joung HWANG ${ }^{3}$, \\ Seon-Hwa LEE ${ }^{4}$, Jin-Heon KWON ${ }^{4}$, Sung-Min KWON ${ }^{4}$, \\ Nam-Hun KIM ${ }^{4 *}$ and Tetsuo KONDO ${ }^{5}$
}

(Received June 30, 2010 and accepted July 9, 2010)

\begin{abstract}
Sentang wood (Melia excelsa Jack) is one of the promoting fast growing tree species that can be introduced in timber estates and community forest in Indonesia. The objective of this research was to evaluate physical, mechanical and durability of Oriented Strand Board (OSB) made from Sentang wood under various pre-treatment techniques including immersing in hot water, immersing in preservative solution and steamed. Three-layered OSBs were manufactured. The strand composition for face, core, and back was $25 \%, 50 \%$ and $25 \%$, respectively. Methane di-isocyanate (MDI, Type H3M) resin was used as an adhesive in amount of $7 \%$. The amount of paraffin used was $1 \%$ based on oven dried strand. The strands were immersed in hot water at $80^{\circ} \mathrm{C}$ for 2 hours, immersed in $2.5 \%$ of CCB preservative solution for 48 hours and steamed at $126{ }^{\circ} \mathrm{C}$ at $1.4 \mathrm{~kg} \cdot \mathrm{cm}^{-2}$ pressure for 1 hour prior to be blended with adhesive. The results indicated that OSB manufactured mostly consisted of quarter round and flat strands with high slenderness ratio and high aspect ratio. Pre-treatment of strand by immersing strands in hot water, immersing in preservative solution and steamed resulted in improvement of water absorption of board, some mechanical properties and durability of OSB. Introducing $2.5 \% \mathrm{CCB}$ preservative on the OSB significantly improved durability of OSB against termite attack but did not influence the strength of OSB. Untreated OSB, OSBs prepared from preserved strands and steamed strands can be used for exterior application, while OSB prepared from hot water immersed strands only can be used for interior application. All OSB parameters manufactured in this experiment were superior when compared with the minimum requirement of CSA 0437.0 standard for Grade O-2 OSB.
\end{abstract}

\section{INTRODUCTION}

The trend of wood supply from natural forests for wood industries in Indonesia showed sharply decreased in the last decade. On the other hand, due to the lack of wood supply as raw materials for wood industries in Indonesia, the cost of wood occupied about $60 \sim 65 \%$ of the product price (BRIK, 2007). It was reported that up to the first quarter 2008 , the total areas of timber estates developed in Indonesia are around 3.032 million hectares (Ministry of Forestry of Indonesia, 2008). It is predicted that in near future the supply of wood from timber estates and community forests will play a dominant role in substituting the wood supply from natural forests in Indonesia. Unfortunately, most of the wood extracted from community forests belong to the lower quarified

Department of Forestry, Faculty of Agriculture, North Sumatera University, Indonesia

${ }^{2}$ Department of Forest Products, Faculty of Forestry, Bogor Agricultural University, Gd. Fahutan Kampus IPB Dramaga, Bogor 16680, Indonesia

${ }^{3}$ Division of Wood Processing, Department of Green Resources Utilization, Korea Forest Research Institute, 57 Hoegiro, Dongdaemun-gu, Seoul 130-712, Korea

${ }^{4}$ Department of Forest Biomaterials Engineering, College of Forest and Environmental Sciences, Kangwon National University, 200-701, Chuncheon, Korea

${ }^{5}$ Laboratory of biomaterial design, Division of Sustainable Bioresources Science, Department of Agroenvironmental Sciences, Faculty of Agriculture, Kyushu University Fukuoka 812-8581, Japan

* Corresponding author (E-mail: kimnh@kangwon.ac.kr) wood than those with medium density with small diameter and wide variety in species. It also contains a lot of natural defect (i.e, checks, knots etc) and has a low dimensional stabilization and low natural durability. Hence, the types of wood are not suitable for solid wood, but very promising as raw materials for wood composites product.

Oriented strand board (OSB) is a structural panel suitable for a wide range of construction and industrial applications. It is a mat-formed panel made of strands sliced in the long direction from small diameter, fast growing round wood logs and bonded with an exteriortype binder under heat and pressure (Structural Board Association, 2005). OSB was manufactured in a crossoriented pattern similar to plywood to create a strong, stiff structural panel (APA, 2009). OSB is composed of thin rectangular-shaped wood strand arranges in layers at right angles to one another, which are laid up into mats that form a panel. OSB is bonded with fully waterproof adhesive.

Sentang wood (Melia excelsa Jack) is one of the promising fast growing tree species that can be introduced in timber estates and community forest. $M$. excelsa has a medium fiber length and a lumen diameter, where as the fiber diameter and cell wall thickness are categorized to the thin medium. M. excelsa also has a small pore diameter, and therefore it is predicted that this wood belongs to a low permeability wood. The tangential, radial and longitudinal shrinkages rates of $M$. excelsa are $5.0 \%, 4.3 \%$, and $1.80 \%$, respectively. $M$ excelsa wood has a bulk density around $0.42-0.52$ to be catego- 
rized as a medium density wood. This wood has a low compression strength and a medium low bending strength. M. excelsa belongs to non durable wood based on grave yard test performance (Iswanto, 2008). The extractive content of $M$. excelsa after dissolved in cold water, hot water, $1 \%$ sodium hydroxide $(\mathrm{NaOH} 1 \%)$ and alcohol-benzene were in the range of $4.25 \sim 5.07 \%$, 7.39 7.83\%, 9.29 11.19\%, and 2.09 2.64\%, respectively (Iswanto, 2008). Based on the above information $M$. excelsa wood can be used for light construction, furniture, panel and veneer. Hence, $M$. excelsa wood is also promising to be used as a raw material for OSB product.

In order to open passways for usage of the above wood, the objective of this research was to evaluate the effect of pre-treatment techniques (i.e., immersing in hot water, preservative solution and steamed) on physical, mechanical and durability properties of OSB made from Sentang wood (M. excelsa).

\section{MATERIALS AND METHODS}

\section{Materials}

M. excelsa wood was collected from Arboretum of Faculty of Forestry, Bogor Agricultural University, Bogor, Indonesia. The strands were produced by using disk flaker. The size of strand used was $60 \sim 70 \mathrm{~mm}$ (1), 28 30 mm (w), and 0.6 0.7 mm (t). Commercial Methane di-isocyanate (MDI, Type H3M) as an adhesive was used to bind the strands. The amount of MDI adhesive and paraffin used were $7 \%$ and $1 \%$ based on oven dry (OD) weight of strand, respectively. Chromate-copper-boron (CCB) preservative was used in amount of $2.5 \%$. The moisture content (MC) of strand was 7\%.

\section{Strand manufacturing}

To set the strand width, the wood materials were cut into planks with dimensions of $2,000 \times 25 \mathrm{~mm}$ in length and thickness by using band saw. To set the strand length, planks were cut into small blocks with dimensions of $70 \times 25 \mathrm{~mm}$ in length and thickness by using circular saw. The disk-flaker used to manufacture the strands determined the thickness of the strands. The thickness depended on the width of the gap between the cutting knife and the disc.

\section{Treatment of strands}

A part of strands was immersed in hot water at $80{ }^{\circ} \mathrm{C}$ for 2 hours, immersed in $2.5 \%$ CCB preservative solution for 48 hours, and steamed in an autoclave at $126^{\circ} \mathrm{C}$ at $1.4 \mathrm{~kg} / \mathrm{cm}^{2}$ for 1 hour. Then, the strands were dried in the oven at $75 \sim 80^{\circ} \mathrm{C}$ for several days to reach about $3 \%$ of the MC. For comparison, untreated strands were also prepared.

\section{Manufacturing of OSB}

Three layered OSB were produced with the size of 30 by 30 by $0.9 \mathrm{~cm}^{3}$ and the target density was $0.7 \mathrm{~g} / \mathrm{cm}^{3}$. The OSB layers were hand-made with face and back layers aligned perpendicular to the core layer. The weight ratio of the face-to-core-to-back layers were set at
1:2:1. Rotary drum blender was used for mixing strand, adhesive and paraffin. After the mat was hot-pressed at $160{ }^{\circ} \mathrm{C}$ under $25 \mathrm{~kg} / \mathrm{cm}^{2}$ as the pressure for $6 \mathrm{~min}$, the board was conditioned for three weeks in a room adjusted in the range of $25 \sim 30^{\circ} \mathrm{C}$ and $60 \sim 65 \%$. Three boards were prepared for each treatment.

\section{Determination of physical and mechanical proper- ties}

Prior to physical, mechanical and durability against termite attack tests, specimens were conditioned for 7 days in a room adjusted at $25 \sim 30^{\circ} \mathrm{C}$. The board parameters measured were air-dry density, MC, water absorption (WA), thickness swelling (TS), linear expansion (LE), modulus of rupture (MOR) and modulus of elasticity (MOE) in bending, and internal bond (IB). The dimension of specimens for evaluation in air-dry density and $\mathrm{MC}$ of boards is 100 by 100 by $9 \mathrm{~mm}^{3}$. The specimens were weighed immediately after dried in the oven at $103 \pm 2{ }^{\circ} \mathrm{C}$ until they reached constant weight. For WA, TS and LE tests, the dimension of specimens is 50 by 50 by $9 \mathrm{~mm}^{3}$. The specimens were also weighed immediately. Average thickness was determined by taking several measurements at specific locations. After 24 hours of submersion, specimens were dripped and wiped for cleaning of any surface water, the weight and thickness of specimens were measured. Mechanical properties (MOE, MOR, and IB) were tested by using universal testing machine (UTM) equipped with a load cell with a capacity of $10,000 \mathrm{~N}$. The dimension of specimens in bending tests is 200 by 50 by $9 \mathrm{~mm}^{3}$. MOE and MOR were measured both in dry and wet states in their long dimension parallel to the major axis of panel. While for IB test, the dimension of specimens is 50 by 50 by $9 \mathrm{~mm}^{3}$. Evaluation of MOE, MOR, and IB parameters were per-

Table 1. Resistance level of wood against termite attacked based on Antifeedant classification

\begin{tabular}{ccc}
\hline Class & Antifeedant value (\%) & Resistance level \\
\hline IV & $75 \leq \mathrm{x}<100$ & very strong \\
III & $50 \leq \mathrm{x}<75$ & strong \\
II & $25 \leq \mathrm{x}<50$ & moderately strong \\
I & $0 \leq \mathrm{x}<25$ & weak \\
\hline
\end{tabular}

Source: Sornnuwat et al. (1995)

Table 2. Resistance level of wood against termite attacked based on termite mortality

\begin{tabular}{cl}
\hline Mortality (\%) & Resistance level \\
$\geq 95$ & very strong \\
$75 \leq \mathrm{x}<95$ & strong \\
$60 \leq \mathrm{x}<75$ & fairly strong \\
$40 \leq \mathrm{x}<60$ & moderately strong \\
$25 \leq \mathrm{x}<40$ & fairly weak \\
$5 \leq \mathrm{x}<25$ & weak \\
$<5$ & in-active
\end{tabular}

Source: Sornnuwat et al. (1995) 
formed at $28^{\circ} \mathrm{C}$ and $60 \%$ R.H. The crosshead speed was adjusted at $10.00 \mathrm{~mm} / \mathrm{min}$.

The resistance of OSB against subterranean termite (Coptotermes curvignathus Holmgren) attack.

The resistance of OSB against subterranean termite (C. curvignathus) attack was determined through a modified wood block test. Samples with the dimension of 20 by 20 by $10 \mathrm{~mm}^{3}$ ( $\left.1 \times w \times t\right)$ were exposured for 4 weeks to termites in order to obtain weight loss, antifeedant and termite mortality parameters. Before and after the tests, the samples were dried in the oven at $103 \pm 2{ }^{\circ} \mathrm{C}$ for determining of weight loss and antifeedant. Antifeedant was determined by calculating the ratio between weight loss of untreated and treated samples. Table 1 and 2 showed the resistance level of wood against termite attack based on antifeedant and mortality classification.

\section{Analysis}

For physical and mechanical properties, all multiple comparisons were subjected to an analysis of variance (ANOVA). Highly significant $(\alpha \leq 0.01)$ and significant ( $\alpha \leq 0.05$ ) differences between mean values of the untreated and treated specimens were determined using Duncan's multiple range tests.

\section{RESULTS AND DISCUSSION}

\section{Strand geometry and curling}

Strand geometry is a prime parameter affecting both board properties and its manufacturing process. Suchsland and Woodson (1991) suggested that strand geometry is of greater significance in the development of board properties than the actual mechanical properties of the fibers themselves. It has a definite relationship with the compression ratio, and thus it will influence the density of the composite board. The slenderness and aspect ratios were calculated based on the ratio of strand length to strand thickness and strand length to strand width, respectively (Maloney, 1993).

The mean values of length, width, thickness, slenderness ratios and aspect ratios of the strands and their distribution used in this study are presented in Table 3, Fig. 1 and Fig. 2. The respective mean values obtained in this experiment were $70.52 \mathrm{~mm}$ in length, $23.68 \mathrm{~mm}$ in width and $0.87 \mathrm{~mm}$ in thickness, yielded slenderness ratio 85.59 and aspect ratio 2.99. The slenderness of strands produced was varied from 55.06 to 108.12. The higher the slenderness ratios resulted in the better contact area

Table 3. Dimension, slenderness ratio and aspect ratio of strand

\begin{tabular}{lccc}
\hline Parameter & Average & Minimum & Maximum \\
\hline Length (mm) & $70.5 \pm 1.0$ & 64.1 & 71.7 \\
Width (mm) & $23.7 \pm 1.1$ & 21.4 & 25.3 \\
Thickness (mm) & $0.9 \pm 0.2$ & 0.3 & 1.2 \\
Slenderness & $85.6 \pm 23.3$ & 55.1 & 108.1 \\
Aspect ratio & $2.9 \pm 0.1$ & 2.7 & 3.4 \\
\hline
\end{tabular}

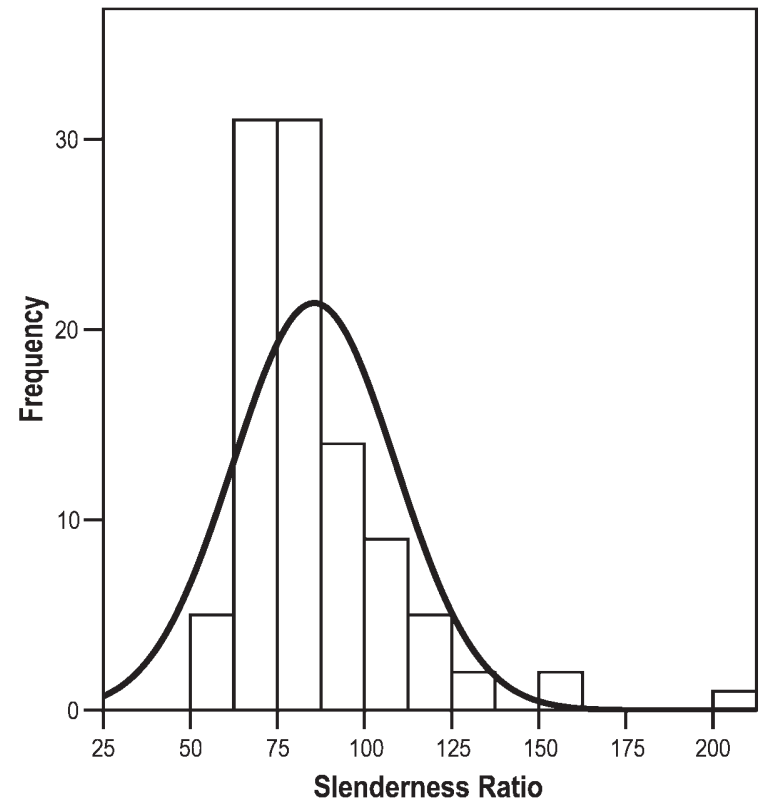

Fig. 1. Distribution of strand slenderness ratios of Sentang wood (M. excelsa).

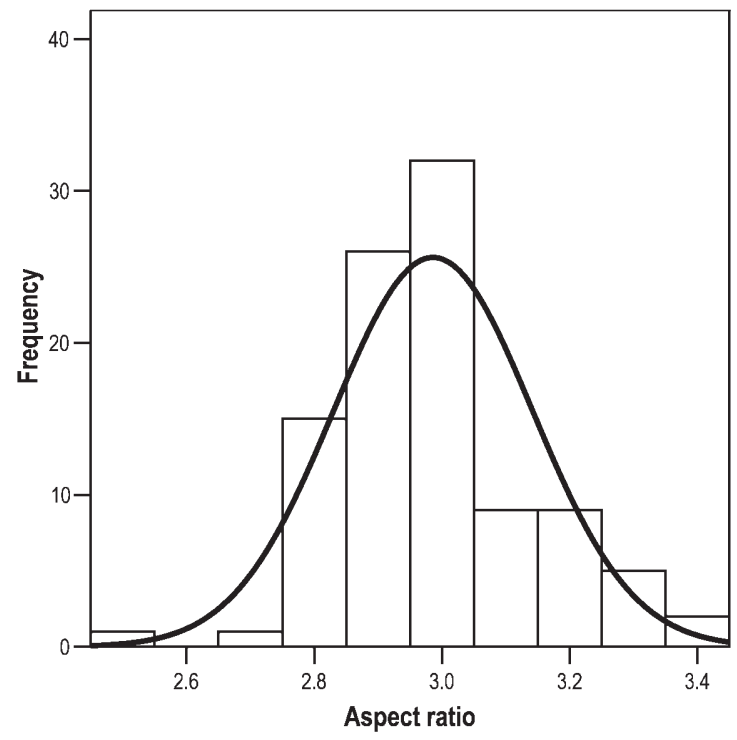

Fig. 2. Distribution of strand aspect ratios of Sentang wood ( $M$. excelsa).

in the mat, the better mechanical properties of finished board and less consumption of binder in the board (Moslemi, 1974) were provided. The strands aspect ratio ranged from 2.73 to 3.43 in which all ratios were above 2. A particle cannot be oriented if having aspect ratio of one (square shape). Maloney (1993) stated that wood strands having an aspect ratio greater than one are easily oriented during forming process. According to Shuler et al. (1976) and Kuklewski et al. (1985), a strand aspect ratio of two is enough to produce OSB with superior properties. The results showed that the strands of $M$. excelsa yielded a high slenderness ratio and a high aspect ratio.

Characteristics of strand curling were listed in Table 4. The results showed that strand thickness significantly 
Table 4. The curliness of strand

\begin{tabular}{lcccc}
\hline Class & $\begin{array}{c}\text { Strand } \\
(\%)\end{array}$ & $\begin{array}{c}\text { Length } \\
(\mathrm{mm})\end{array}$ & $\begin{array}{c}\text { Width } \\
(\mathrm{mm})\end{array}$ & $\begin{array}{c}\text { Thickness } \\
(\mathrm{mm})\end{array}$ \\
\hline 1. Flat & 33 & 70.5 & 23.6 & 0.9 \\
2. Curl, quarter round & 55 & 70.5 & 23.7 & 0.8 \\
3. Curl, half round & 12 & 70.4 & 23.6 & 0.7 \\
\hline
\end{tabular}

n: 100 strands

affected the curling of strand, while the strand length and width showed no significant effects. The thicker strand tends to be more flat when compared with the thin one which tends to curl up easier. OSBs manufactured in this experiment mostly consisted of quarter round strands and flat strands which are suitable to manufacture OSB panels. Strand shape for OSB manufacture should be rectangular, thin, long and narrow. Ideal strand should also be straight and flat without curling, because a higher curling of strands can bring the same trouble in the adhesion between strand and adhesive, which could also affected on board properties manufactured (Maloney, 1993). A study by Misran (2005) suggested that rubber wood strands tended to curl when it was produced by using disk flaker. A similar problem was encountered in this study where the strands were found to warp on one side of its surface.

\section{Properties of OSB made from Sentang wood (Melia excelsa Jack) under various pre-treat- ments techniques}

M. excelsa belongs to non durable wood and contains a relatively high amount of extractives (Iswanto, 2008). In order to improve quality of the final product of OSB, the evaluation of the physical properties (i.e., density, MC, WA, TS, and LE) and mechanical properties (i.e., MOR, MOE, and IB) of OSB made from $M$. excelsa together with its resistance against subterranean termite (C. Curvignathus) attack (i.e., weight loss, antifeedant and mortality) were conducted under various pre-treatment techniques, namely immersing in hot water, immersing in preservative solution and steamed.

\section{Physical properties of OSB}

The mean values of air-dried density and MC of OSB were varied between 0.58 to $0.60 \mathrm{~g} / \mathrm{cm}^{3}$, and 8.59 to $11.80 \%$, respectively. The air-dried density obtained in this experiment was lower than the target density of $0.70 \mathrm{~g} / \mathrm{cm}^{3}$ (Table 6). It was due to a spring back of the board during pressing and swelling in the board conditioning. After pressing, the resulted board thickness exceeded the thickness target of $9.00 \mathrm{~mm}$. The lowest and the highest MC values were provided from OSBs prepared from hot water immersed strands and untreated strands, respectively. However, a statistical analysis showed that all pre-treatments for strands adopted in this experiment do not significantly affect the air-dried density and MC parameters.

The mean values of WA, TS and LE after immersing in cold water for 24 hours were varied between 22.30 to $42.24 \%, 6.89$ to $7.63 \%$, and 0.85 to $1.04 \%$, respectively
(Table 6). The lowest and the highest WA values were obtained on OSBs prepared from preserved strands and untreated strands, respectively. The similar phenomenon occurred the parameter. On the other hand, the lowest and highest values of TS were obtained by OSBs prepared from steamed strands and untreated strands, respectively. The strand pretreatment had a significant effect on the WA parameter, whereas the TS and LE parameters were not significantly affected by the strand pre-treatment.

Pre-treatment of strands by immersing in hot water, preservative solution and steamed decreased the WA value of OSB. It was presumably due to some extractives removed during the pre-treatment of strands. Extractives can cause poor water resistance properties of the finished products (Maloney, 1993). Furthermore, MDI resin is very sensitive to wood extractives. The value of extractives of $M$. excelsa dissolved in cold water and hot water are varied in the range of 4.25 5.07\%; respectively (Iswanto, 2008). Pre-treatment of strands by steam improved the WA value, which agreed with the result of Rowell et al. (2002) that had prepared fiberboard from steamed fibers. It is also interesting to note that the treatment of strands with preservative solution gave a positive effect on dimensional stability of OSB prepared from M. excelsa. Although CSA 0437.0 standard for Grade O-2 OSB (SBA, 2004) dose not require WA and LE parameters, all the TS values obtained in this experiment met the requirement of CSA 0437.0 standard for Grade O-2 OSB (SBA, 2004).

\section{Mechanical properties of boards}

The mean values of MOR in parallel to the grain direction of OSB both in dry and wet states were $39 \mathrm{MPa}$ and $18 \mathrm{MPa}$; $61 \mathrm{MPa}$ and $6 \mathrm{MPa}$; $34 \mathrm{MPa}$ and $16 \mathrm{MPa}$; and $44 \mathrm{MPa}$ and $20 \mathrm{MPa}$, respectively for untreated, hot water immersed, immersed in preservative solution, and steamed boards, as listed in Table 6. The highest and the lowest values of MOR in the dried state condition were achieved on boards prepared from strands immersed in hot water and boards prepared from preserved strands respectively. The highest and the lowest values of MOR in the wet condition were achieved on steamed boards and boards immersed in hot water, respectively. Furthermore, the mean values of MOE of the same specimens were 4,460 $\mathrm{MPa}$ and $1,900 \mathrm{MPa} ; 6,460 \mathrm{MPa}$ and $960 \mathrm{MPa}$; 5,500 $\mathrm{MPa}$ and 2,050 MPa; and 6,010 MPa and $2,510 \mathrm{MPa}$, respectively for untreated, hot water immersed, immersed in preservative solution and steamed boards, also as listed in Table 6 . The highest and the lowest values of MOE in the dry state condition were achieved on boards prepared from hot water immersed strands and untreated strands, respectively. The highest and the lowest values of MOE in the wet condition were achieved on steamed boards and hot water immersed boards, respectively.

It is clear that the pre-treatment of strands in hot water at $80^{\circ} \mathrm{C}$ for 2 hour significantly improved the MOR and MOE values in the dry state condition. The results also indicated that a control board, boards prepared 
from preserved strands and boards prepared from steam strands have similar values of MOR and MOE in the dry state condition. However, boards prepared from steam strands tend to result in higher values of MOR and MOE. Boards prepared from preserved strands tend to result in a higher value of MOE (Table 6). However, when bending strength was measured in the wet state condition, the MOR and MOE values of boards prepared from hot water immersed strands were lower than 3 other treatments (i.e., untreated, immersed in preservative solution and steamed boards). Among others, boards prepared from steam strands showed a superior bending strength in the wet condition.

Extractives are not a part of the wood structure. They include tannins and other polyphenolics, coloring matters, essential oils, fats, resins, waxes, gums, starch, and simple metabolic intermediates (Maloney, 1993). They can be removed by use of appropriate solvents. The extractives cause some problems in particleboard manufacturing i.e., consumption of resin and its curing rate, poor water resistance properties of the finished products, and a blow problem during the pressing. It is known that immersing the strands in cold and hot water dissolved such wood extractives. The presence of the extractives can block the adhesive penetration into the wood particles, resulting in the lower mechanical properties of particle boards achieved (Maloney, 1993). Immersing the strands in hot water can provide an improvement of the surface tension of strands and the adhesion of strands and adhesives (Alamsyah, et al., 2008). Thus, it can also improve the strength of the composite. It was reported that the strength of OSB prepared from Acacia mangium wood strands and flake boards prepared from red meranti wood flakes (Shorea leprosula) was much improved after the strands/parti- cles were immersed in hot water for 2 hours (Febrianto et al., 2009; Hadi, 1988). Furthermore, heat treatments on wood particles could cause a decrease in acidic degrees of wood by forming acetic acid and formic acid. The acids hydrolyzed celluloses and hemicelluloses result in reducing of mechanical properties (Boonstra et al; 2006). In fact, we observed that delamination occurred on the OSB prepared from hot water immersed strands after they were immersed in cold water prior to be tested in the wet condition.

Strength retention is defined as a ratio between MOR or MOE in a wet state to MOR or MOE in a dry condition. The higher the strength retention value, the more suitable the board for exterior application (Massijaya and Okuma, 1996). Table 6 also exhibits the strength retention of OSB prepared under various pre-treatment techniques. Based on the strength retention value obtained in this experiment, it can be said that untreated OSB and OSB prepared from preserved and steamed strands can be used under severe condition considering exterior application. Although OSB prepared from hot water immersed strands had the most superior value of MOR and MOE in the dry condition, this type of OSB can only be used for structural interior application. Nuryawan et al. (2008) reported that OSB made from untreated strands of Acacia mangium, Eucalyptus sp. and Gmelina arborea bonded with MDI resin can be used for exterior application.

The mean values of IB of OSB prepared from untreated, hot water immersed, immersed in preservative solution and steamed strands were $0.5,0.9,0.5$, and 1.9 $\mathrm{MPa}$, respectively. The highest and the lowest values of IB were achieved on boards prepared from steamed strands and preserved strands, respectively. The pretreatment of strands by steam prior to board manufac-

Table 5. Resistance of OSB against termite attack based on antifeedant and termite mortality

\begin{tabular}{lccccc}
\hline Treatment & Weight loss (\%) & \multicolumn{2}{c}{ Antifeedant (\%) } & \multicolumn{2}{c}{ Mortality (\%) } \\
\hline Control & 7.5 & - & (weak) & 40.0 & (moderately strong) \\
Hot Water Immersed & 5.5 & 15.4 & (strong) & 64.6 & (fairly strong) \\
Preservative Solution & 0.6 & 85.1 & (weak) & 100.0 & (very strong) \\
Steamed & 8.9 & 8.1 & (weak) & 52.0 & (moderately strong) \\
\hline
\end{tabular}

Table 6. Effect of Pre-Treatment Techniques on Physical and Mechanical Properties of OSB Prepared from Sentang wood (M. excelsa Jack)

\begin{tabular}{|c|c|c|c|c|c|c|c|c|c|c|}
\hline \multirow[t]{2}{*}{ Treatment } & \multirow{2}{*}{$\begin{array}{l}\text { WA } 24 \mathrm{H} \\
(\%)\end{array}$} & \multirow{2}{*}{$\begin{array}{l}\text { TS } 24 \mathrm{H} \\
(\%)\end{array}$} & \multirow{2}{*}{$\begin{array}{l}\mathrm{LE} 24 \mathrm{H} \\
\quad \%)\end{array}$} & \multicolumn{2}{|c|}{$\begin{array}{l}\text { MOR } \\
(\mathrm{MPa})\end{array}$} & \multicolumn{2}{|c|}{$\begin{array}{l}\mathrm{MOE} \\
(\mathrm{MPa})\end{array}$} & \multicolumn{2}{|c|}{$\begin{array}{c}\text { Strength Retention } \\
(\%)\end{array}$} & \multirow[t]{2}{*}{$\begin{array}{c}\mathrm{IB} \\
(\mathrm{MPa})\end{array}$} \\
\hline & & & & Dry & Wet & Dry & Wet & MOR & $\mathrm{MOE}$ & \\
\hline Untreated & $42.24 \pm 5.56^{c}$ & $7.63 \pm 2.04$ & $0.92 \pm 0.21$ & $39 \pm 10^{\mathrm{a}}$ & $18 \pm 4^{b}$ & $4460 \pm 590^{\mathrm{a}}$ & $1900 \pm 210^{\mathrm{b}}$ & $46.27 \pm 3.31$ & $42.68 \pm 0.86$ & $0.5 \pm 0.1^{\mathrm{a}}$ \\
\hline HWI & $28.51 \pm 2.94^{\mathrm{ab}}$ & $7.46 \pm 1.06$ & $1.04 \pm 0.06$ & $61 \pm 11^{\mathrm{b}}$ & $6 \pm 1^{\mathrm{a}}$ & $6460 \pm 490^{\mathrm{b}}$ & $960 \pm 100^{\mathrm{a}}$ & $9.95 \pm 1.27$ & $14.64 \pm 2.79$ & $0.9 \pm 0.3^{\mathrm{a}}$ \\
\hline PSI & $22.30 \pm 2.92^{\mathrm{a}}$ & $7.02 \pm 1.64$ & $0.85 \pm 0.15$ & $34 \pm 10^{\mathrm{a}}$ & $16 \pm 2^{\mathrm{b}}$ & $5500 \pm 760^{\mathrm{ab}}$ & $2050 \pm 110^{\mathrm{b}}$ & $49.78 \pm 12.54$ & $37.84 \pm 6.93$ & $0.5 \pm 0.1^{\mathrm{a}}$ \\
\hline Steam & $32.45 \pm 2.11^{\mathrm{b}}$ & $6.89 \pm 0.51$ & $0.93 \pm 0.08$ & $44 \pm 7^{\mathrm{ab}}$ & $20 \pm 2^{\mathrm{b}}$ & $6010 \pm 1270^{\mathrm{ab}}$ & $2510 \pm 190^{\circ}$ & $47.01 \pm 9.68$ & $43.15 \pm 10.52$ & $1.9 \pm 0.2^{\mathrm{b}}$ \\
\hline $\begin{array}{l}\text { CSA } 0437.0 \\
\text { (Grade O-2) } \\
\text { standard }\end{array}$ & N/A & $\leq 15$ & N/A & 296 & N/A & 56084 & N/A & N/A & N/A & 3.52 \\
\hline
\end{tabular}

Notes: HWI: Hot water immersed; PSI: Preservative solution immersed; Homogeneity group: Same letters in each columns indicated that there is no significant difference between the samples according to the Duncan's multiple range test. $p$ : 0.01 . 
turing improved the IB value significantly. The IB value of OSB prepared from steamed strands was about 2 4 times higher than those of OSBs prepared from preserved strands, untreated strands and hot water immersed strands. In the steam treatment, free sugars in wood particles were converted into furan intermediates. Then, furan intermediates can be converted into furan resin, resulting in improvement in IB values and dimensional stability of board. This result agreed with the previous result of fiberboards prepared from steamed fibers reported by Rowell et al. (2002).

Almost all mechanical parameters of OSB except MOE of untreated boards prepared in this experiment were higher than the minimum requirement in the properties according to CSA 0437.0 standard for Grade O-2 OSB (SBA, 2004).

\section{The resistance of OSB against subterranean ter- mite (Coptotermes curvignathus Holmgren) attack}

Subterranean termite gives the worst damage in wood and wood products deterioration in the tropical region. Subterranean termite utilizes wood both as a shelter and food sources. As $M$. excelsa wood belongs to non durable wood (Iswanto, 2008), the resistance of OSB from M.excelsa strands against subterranean termite (C. curvignathus) attack under various pre-treatment techniques was observed.

The mean value of weight loss of samples after baited for 4 weeks to subterranean termite (C. Curvignathus) ranged between $0.61 \sim 8.90 \%$. The lowest and the highest values of the weight loss were achieved on OSB prepared from preserved strands and steamed strands, respectively (Table 5). Based on the antifeedant criteria, the untreated, hot water immersed and steamed treatments showed a similar resistance to subterranean termite (C. Curvignathus), indicating weak or less resistance. On the other hand, OSB prepared from preserved strands exhibited a strong resistance to subterranean termite (C. Curvignathus). An almost similar phenomenon occured when the resistance of OSB was measured based on the termite mortality criteria. The lowest and the highest termite mortality were obtained on OSB prepared from the untreated and preserved strands, respectively. The untreated board, boards prepared from steamed strands were categorized to moderately strong, while OSB prepared from hot water immersed strands and preserved strands were categorized to fairly strong and very strong resistance to subterranean termite $(C$. Curvignathus) under the adopted experimental condition.

\section{CONCLUSIONS}

OSB manufactured mostly consisted of quarter round and flat strands with a high slenderness ratio and a high aspect ratio. The pre-treatments of strands by immersing strands in hot water, immersing in preservative solution and steamed improved water absorption of OSB and some mechanical properties in addition to durability of OSB. OSB prepared from hot water immersed strands has very excellent physical and mechanical properties in a dry state condition, but it provided a very low strength retention value. OSB prepared from steamed strands had excellent physical and mechanical properties both in the dry and wet states. OSB prepared from preserved strands had the same quality as the untreated OSB in terms of physical and mechanical properties, but it showed a strong resistance against termite attack. Therefore, untreated OSB, OSB's prepared from preserved strands and steamed strands can be used for exterior application, while OSB prepared from hot water immersed strands only can be used for interior application.

\section{REFERENCES}

Alamsyah, E. M., M. Yamada M and K. Taki 2008 Bondability of tropical fast-growing tree species III: Curing behaviour of resorcinol formaldehyde resin adhesive at room temperature and effects of extractives of Acacia mangium wood on bonding. J Wood Sci., 54: 208-213

APA 2009 Oriented strand board: Product guide. The Engineered Wood Association, USA

Badan Revitalisasi Industri Kehutanan 2007 Hutan rakyat: Peran yang makin nyata. BRIK INFO 4: 1-2

Boonstra, M. J., A. Pizzi, F. Zomers, M. Ohlmeyer and W. Paul 2006 The effects of a two stage heat treatment process on the properties of particleboard. Holz Roh-Werkst 64: 157164

Febrianto, F., L. I. Royama, W. Hidayat, E. S. Bakar, J. H. Kwon and N. H. Kim 2009 Development of oriented strand board from acacia wood (Acacia mangium Willd.): Effect of pretreatment of strand and adhesive content on the physical and mechanical properties of OSB. J Wood Sci and Tech 37: $121-127$

Hadi, Y. S. 1988 Pengaruh perendaman panas partikel kayu terhadap stabilitas dimensi papan partikel meranti merah. $J$ Teknologi Hasil Hutan 2: 16-24

Iswanto, A. H. 2008 Basic properties of Sentang wood (Melia excelsa Jack) and its utilization as oriented strand board materials. [Thesis]. Bogor: Posgraduated School, Bogor Agricultural University

Kuklewski, K. M., P. R. Blankenhorn and L. E. Rishel 1985 Comparison of selected physical and mechanical properties of red maple (Acer rubrum L.) and aspen (Populus grandidentata Michx.) flakeboard. Wood and Fiber Sci 17: $11-21$

Maloney, T. M. 1993 Modern particleboard and dry process fiberboard manufacturing. Hal Leonard Corp

Massijaya, M. Y, and M. Okuma 1996 Development of boards made from waste newspapers I. Production and fundamental properties of waste newspaper boards, Mokuzai Gakkaishi, 42: 1243-1249

Ministry of Forestry Republic of Indonesia 2008 Forestry statistics of Indonesia 2007

Misran, S. 2005 Evaluation of oriented strand board made from rubberwood using phenol formaldehyde as a binder. [Thesis]. University Putra Malaysia

Moslemi, A. A. 1974 Particleboard: Technology. Vol 2 of Particleboard. Southern Illinois University Press (USA)

Nuryawan, A., M. Y. Massijaya and Y. S. Hadi 2008 Physical and mechanical properties of oriented strand board (OSB) made of small diameter akasia (Acacia mangiumn Willd.), ekaliptus (Eucalyptus sp.) and gmelina (Gmelina arborea Roxb.): Influence of wood species and adhesive bonded type. Journal Ilmu dan Teknologi Hasil Hutan 1: 60-66

Rowell, R., S. Lange, J. McSweeny and M. Davis 2002 Modification of wood fiber using steam. Proceeding of 6th Rim Bio-Based Composites Symposium. Oregon, USA

OSBA 2004 Oriented Strand Board in Wood Frame 
Construction. Structural Board Association. Canadian Edition 2004, pp. 6

Schuler, A., M. Bumgardner, B. Hansen and B. Luppold B 2001 Implications of the rising use of hardwoods in OSB. Engineered Wood J. 4: 29-32

Sornnuwat, Y., C. Vongkaluang, T. Yoshimura, K. Tsunoda and M. Takahashi 1995 Tunneling of subterranean termites,
Coptotermes gestroi Wasmann and Coptotermes formosanus Shiraki, into gravel physical barriers. Japanese $J$ Environmental Entomology and Zoology 7: 13-19 Suchland, O. and G. E. Woodson 1991 Fiberboard manufacturing practices in the United States. Forest Products Research Society. Agriculture Handbook 640, pp. 263 